\title{
Title:
}

\section{Identification of challenges to the availability and accessibility of opioids in twelve European countries: conclusions from two ATOME six-country workshops}

\section{Authors:}

\author{
Linge-Dahl $L^{1}$, Vranken $M J M^{2}$, Juenger $S^{3}$, North $K^{4}$, Scholten $W^{5}$, Payne $S^{6}$, ? \\ Radbruch $L^{18}$ \\ ${ }^{1}$ University Hospital Bonn, Department of Palliative Medicine Bonn, Germany \\ ${ }^{2}$ Utrecht Institute for Pharmaceutical Sciences, Division of Pharmacoepidemiology \& Clinical Pharmacology, \\ Utrecht University, Utrecht, the Netherlands \\ ${ }^{3}$ Institute of General Medicine, Hannover Medical School, Hannover, Germany \\ ${ }^{4}$ Help the Hospices, London, United Kingdom \\ ${ }^{5}$ Consultant - Medicines and Controlled Substances, Lopik, the Netherlands \\ 6 International Observatory on End-of-Life Care, Division of Health Research, Lancaster University, Lancaster, \\ Lancashire, United Kingdom \\ ${ }^{8}$ University Hospital Bonn, Department of Palliative Medicine, Bonn, Germany/ Malteser Hospital Seliger Gerhard \\ Bonn / Rhein-Sieg, Palliative Care Centre ,Germany
}

\begin{abstract}
Access to many controlled medicines is inadequate in a number of European countries. This produces deficits in the treatment of moderate to severe pain as well as in opioid agonist therapy. To elaborate the reasons offor this inadequacy, the work plan of the Access to Opioid Medication in Europe (ATOME) project included two sixcountry workshops_. These workshops includedto conduct a national situational analysis, and to elaborate tailor-made recommendations for improvement and drafts of action plans for their implementation. In total, Eighty-four84 representatives of the national Ministries of Health, national controlled substances authorities, experts representing regulatory and law enforcement authorities, and-leading healthcare professionals, and patient representatives from thirteen European countries participated in eitherone of the workshops. The delegates utilized break-out sessions to identify key Common challenges that could be identified during the ATOME workshops were a number ofto opioid accessibility in their country ien the domainlevel of knowledge and educational, regulation and $\theta r y$, legislationna, as well as public awarenessl and training barriers that limit opioid prescription. In addition short validity and bureaucratic practices resulting in an overregulation impeding availablity of some essential medicines. In relation to opioid agonist therapy, stigmatization and criminalisation of people who use drugs remained the major impediment to increasing programme coverage. The challenges identified duringoutcomes of the workshops were the basis for furtherused to inform subsequent dissemination and implementation activities in the ATOME project $_{2}$ and in some countries already theserved as a stepping stone for the first changes in regulations and legislation.
\end{abstract}

\begin{tabular}{|l|}
\hline Formatted: English (U.S.) \\
\hline Formatted: English (U.S.) \\
\hline Formatted: English (U.S.) \\
\hline Formatted: English (U.S.) \\
\hline Formatted: English (U.S.) \\
\hline Formatted: English (U.S.) \\
\hline Formatted: English (U.S.) \\
\hline Formatted: English (U.S.) \\
\hline Formatted: English (U.S.) \\
\hline
\end{tabular}




\section{Identification of challenges to the availability and accessibility of opioids in twelve European countries: conclusions from two ATOME six-country workshops}

\section{Background}

With the exception of some Western industrialized countries, access to many controlled medicines is inadequate around the world [1,2]. The World Health Organization (WHO) estimates that approximately five billion people live in countries with low or no access to controlled medicines [3] and insufficient access to treatment for moderate to severe pain is reported in more than 150 countries. In 12 countries of the European Union (EU), opioid analgesic consumption is described as 'low to very low' [4].

In addition to pain management ${ }_{1}$ opioids are also needed for in the treatment of opioid dependence, mainly substitution programmes like thefor opioid agonist therapy (OAT) for drug users. Access to OAT in the EU varies dramatically. In some Central and Eastern European countries, less than 10\% of people who would benefit from opioid agonist therapy are reached. Where harm reduction programmes exist, access is impeded by lengthy waiting lists, strict admission criteria, and lack of evidence-based standards for provision and quality of care; those at the greatest risk of exclusion are women, young people and migrants [5].

The European Commission's 7th Framework programme funded the Access to Opioid Medication in Europe (ATOME) project (2009-2014, www.atome-project.eu). Its objective wais to improve access to opioids in 12 European countries (Figure 1) where there has been statistical evidence of low per capita morphine consumption at the time of the project submission (09.2009): Bulgaria, Cyprus, Estonia, Greece, Hungary, Latvia, Lithuania, Poland, Slovakia, Slovenia, Serbia and Turkey.

The work plan of the ATOME project (Figure 1) included two international six countryworkshops as the foundation of subsequent activities directed at improving national policies related to opioid access. This article aims to describe the main challenges to opioid availability and accessibility identified during these two workshops and the recommendations for improving access to opioids that were made by the participants of the workshops. 


\section{Methods}

Figure 1: ATOME work plan-map

\begin{tabular}{|c|c|c|c|c|c|c|c|}
\hline $\begin{array}{l}\text { Legislation } \\
\text { review training } \\
{[6]}\end{array}$ & 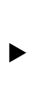 & $\begin{array}{l}\text { "Quick scan" of } \\
\text { legislation [30] }\end{array}$ & $\begin{array}{l}\text { Deep scan of } \\
\text { legislation }\end{array}$ & 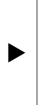 & $\begin{array}{l}\text { Delivery of } \\
\text { country reports }\end{array}$ & 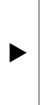 & $\begin{array}{l}\text { Outcome: country-specific } \\
\text { recommendations for } \\
\text { legislation improvement }{ }^{3}\end{array}$ \\
\hline $\begin{array}{l}\text { Six-country } \\
\text { workshops }\end{array}$ & $\checkmark$ & $\begin{array}{l}\text { Outcome: country } \\
\text { for controlled }\end{array}$ & $\begin{array}{l}\text {-specific action plans } \\
\text { substances policy }\end{array}$ & $>$ & $\begin{array}{l}\text { National follow- } \\
\text { up conferences }\end{array}$ & 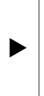 & $\begin{array}{l}\text { Outcome: enhanced } \\
\text { implementation of national } \\
\text { recommendations [32] }\end{array}$ \\
\hline
\end{tabular}

As a part of this project two international six country-workshops were organised Country teams had been composed at the outset of the work programme to ensure country-specific relevance and applicability of the project activities; the teams included representatives of the national Ministries of Health; national controlled substances authorities; experts representing regulatory and law enforcement authorities; leading healthcare professionals; and patient representatives. The sixcountry workshops were held in Bucharest, Romania in September and November 2011, with the purpose to 1) assist expert delegations to undertake national situational analyses, 2) disseminate tailor-made recommendations to their national governments for improving the accessibility, availability and affordability of controlled medicines and 3) plan how to implement these improvements. the aim to undertake national situational analysis, make tailor-made recommendations for improvement and develop action plans to implement these recommendations. This article aims to describe the main challenges to opioid availability and accessibility that were identified during these two workshops and the recommendations for improving access to opioids that were made by the participants of the workshops.

\section{Methods}

Two six country-workshops were organized in Bucharest, Romania in September and November 2011, with the purpose to:

(1) assist expert delegations to undertake national situational analyses

(2) disseminate tailor-made recommendations to their national governments for improving the accessibility, availability and affordability of controlled medicines

(3) plan how to implement these improvements.

Additionally, awareness about tools and resources was intended to be raised.

The guiding principle of each workshop was tITe principle of balance-in national opioid policy, i.e. the obligation ofn each government to ensure availability and 
accessibility of opioids while preventing abuse and diversion was the guiding principle in both workshops. The workshops were designed as two-and-a-half day events with a combination of lectures from international experts (total duration: $5,5 \mathrm{~h}$ ) and discussion groups where theto analyze the national situation was analyzed regarding access to opioids, identify identify potential problems, and decide on furtheraction steps to improve the situation (total duration: 8h)-were prepared. Representatives from the ATOME consortium and the workshop faculty assisted the group work as facilitators. The country teams presented the outcomes of their group work in plenary, followed by a discussion and feedback from the other delegations (total duration: 3,5 hours). Tools such as the WHO checklist for national situation analysis [7]; a case example of a patient in order to discuss the national situation in a problem-based manner; and a strategic action planning worksheet were used in the discussion groups in order to guide the process of tailoring country-specific solutions. Material relevant to the accessibility and availability of opioids, such as scientific articles or position papers, was provided to participants prior to the workshop.-The country teams presented the outcomes of their group work in plenary. Tools such as the WHO checklist for national situation analysis [8]; a case example of a patient in order to discuss the national situation in a problem-based manner; and a strategic action planning worksheet were used in the discussion groups in order to guide the process of tailoring country-specific solutions. - The results of this article have beenwere condensed from the country teamsteam'steams' presentations, action plans and minutes from the group work sessions. The workshops wereas evaluated by a pre- and post-workshop questionnaire.

\section{Results}

Participants

In total, 39 representatives from Bulgaria, Cyprus, Greece, Turkey, Serbia and Slovenia attended the first workshop, and 45 peopledelegates from Estonia, Hungary, Latvia, Lithuania, Poland and Slovakia attended-the second one. Ukraine (which was not oneamong of the target countries) sent observers to the second workshop. Participants forming the country teams were representatives from the national Ministries of Health, national controlled substances authorities, experts representing regulatory and law enforcement authorities; and leading healthcare professionals.

The national delegations utilized break-out sessions to analyse country-specific key challenges to opioid accessibility and to elaborate strategic action plans for improvement, which were subsequently presented and discussed in plenary. 
Lack of education, excessive regulations relating to the prescribing of opioids, "opiophobia" - fear from opioids and lack of reimbursement were

The most frequently-identified as challenges to concerning-access to opioids by 50 75\% of the country teams, see (Table 1). during the ATOME workshops are:

Table 1 shows the most frequently identified challenges and recommendations for improvement made The most frequently

lack of education (identified by 9 country teams); excessive regulations relating to the prescribing of opioids (identified by 8 country teams); "opiophobia" (identified by 7 country teams); lack of reimbursement (identified by 6 country teams); lack of knowledge about opioids amongst patients, their family and society; lack of recognition of pain management; limitations to the formulary availability of opioids; excessive regulations relating to storage and dispensing of opioids; lack of opioid legislation/inappropriate legislation; and treatment of pain in non-cancer patients (identified by 5 country teams). All challenges that were highlightedilidentified challenges during the workshops are presented below and in Ttable 1, followinged by recommendations for improvement made by the participants. - on how to deal with these challenges. TIhe names of the countries mentioned in the following paragraphs can be seen as exemplary; because the the suggestions may relatehave been given by one or more countries during the workshops but can it can be assumed to be applicable to many other countries as well.

Lack of education and training on opioid medicines and their use:

Lack of education and linadequate and inconsistent training of physicians in pain management results in a lack of knowledge regarding the correct dosage of opioids. Where education initiatives exist, they are usually subsumed within the training of other medical specialties and are often only of a few hours duration. In consequence many general practitioners lack expertise in prescribing opioids and usually refer this responsibility to oncologists. This may hamper acess to opioid medicines for patients:

To overcome the challenge regarding the lack of opioid education and training initiatives for healthcare professionals, delegates from cyprus suggested an obligatory examination for that aall doctors should be required by the Head of Pharmaceutical Services/Medical Council to pass an examination regardinglating to opioid prescribing. For Estonia and Hungary it was recommended by participants from the countries to improve opportunities for Continuing Medical Education in the area of pain management, whilst Hungarian delegates recommended that physicians should also be taught practical skills in how to apply the pharmacotherapy of pain. In Serbia there is a need for education/training sessions and opioid workshops amongst regulatory authorities that stress access to pain relief as a 'human right'. Workshop participants from Slovenia recommended developing a network to educate, train and support all members of the multidisciplinary team in prescribing.

tack of knowledge about opioids amongst patients, their family and society

There is aA lack of public awareness about opioids was explicitly mentioned by seven country teams. This involves fears and beliefs amongst patients and their 
families, as well as and the general public. In addition attitudes and beliefs amongst the public in relation to opioids involve much misinformation and misunderstanding in the general public. Many medical professionals are afraid of prescribing opioids. This was explicitly mentioned by seven country teams. Societal misconceptions about opioids lead to negative side-effects such as the perception that suffering is normat, heroic or necessary. Negative stereotypes about opioids ( e.g. labelling opioid medicines as "narcotic drug" or "poison") and fears about tolerance amongst patients and their families reinfoce this problem.In some countries, e.g. Lithuania, there was a perception that national policy discourse or the societal rhetoric around opioids even increases reluctance among general practitioners to provide pain management:

\section{tack of recognition of pain management}

Five country teams reported that chronic pain is often neither recognised nor acknowledged by healthcare professionals and a sceptical attitude towards pain treatment is reported among many physicians. Specialists of other disciplines other than oncology do not always recognise the need for pain management. In some countries, o.g. Lithuania, there was a perception that national policy discourse of the societal hetoric around opioids even increases reluctance among general practitioners to provide pain management:

\section{Treatment of pain in non-cancer patients}

Five countries reported that pain management for non-cancer patients is poorly organised. In some countries opioids are usually limited for use in terminal cancer. Access to palliative care for non-cancer patients is a challenge in many countries; for example it was reported from Latvia that opioids are not reimbursed for patients with non-oncological diseases except for patients suffering from HIVIAIDS.

\section{Lack of reimbursement (particularly for non-cancer patients)}

The costs of opioids, described as very high in many countries, are not always covered by government fundingappropriate statutory funding schemes. This was described as a challenge by six country teams. Particularly for people suffering from acute or chronic conditions due to non-oncological diseases this is a problem since chronic non-cancer pain in some places is not recognised as a medical condition, which makes reimbursement impossible. For people with low or no income, this may mean that they will not have access to the medicines they need.

\section{Limitations to the available range of opioids}

Lack of choice of opioids such as injectable morphine, slow-release oral morphine, buprenorphine and methadone was highlited as one of the challenges in 5 countries. As an example in Slovenia not all medicines from the WHO-ssential medicines list were available. Even though a proposal for a new list had been drafted at the time of the workshop, there was concern that it will not be adhered to by the pharmaceutical industry.

\section{Pharmaceutical company reluctance to manufacture opioids}


In some smaller countries pharmaceutical companies have little interest in procuring opioids as there is only a rather small market where cost of procurement and projected incomes are disproportional. This challenge was reported by three country teams.

\section{Excessive regulations relating to the prescribing of opioids}

Physicians often are reluctant to prescribe opioids due to excessive bureaucracy, as described highlighted by eight country teams. Barriers such as special prescription forms that need to be stored with special security measures, restrictions regarding the authorisation to prescribe (e.g. only designated medical specialties), excessive reporting requirements of opioid prescriptions, and complicated administrative requirements for filling out the prescriptions may result in a reluctance to prescribe opioids for patients in medical need. Other reported challenges to the availability of opioid medicines are a limited prescription validity in combination with restrictions regarding the maximum amount of opioids to be prescribed. In addition it was reported that fear of prosecution if the patient should die deters physicians from prescribing opioids. This may as well result in a lack of experience in prescribing amongst family practitioners. Excessive regulation may also affect provision of opioids in home care settings.

\section{Excessive regulations relating to storage and dispensing of opioids}

Five country teams reported that not all pharmacies are allowed to store opioids and that special storage conditions are required. Extensive bureaucracy relating to the dispensing of opioid medicines often results in a delay in the commencement of treatment with these medicines. Fear of prosecution may also deter medical practitioners from prescribing or dispensing opioids, such as in Greece, where prosecution of pharmacists for minor opioid offences is common so many pharmacies refuse to dispense morphine.

\section{tack of opioid legislation/inappropriate legislation}

A lack of legislation related to the use of opioids, the lack of education that would be necessary to work with opioids and an outdated opioid terminology impede an adequate supply. Complicated legislation structures such as the involvement of three separate Ministries make changes in the opioid legislation extremely difficult. This challenge was reported by five country teams.

\section{Focus on suppression rather than availability of opioids}

Government agencies and committees tend to focus more on prevention of diversion and misuse rather than medical availability of opioids. National governments have little recognition that opioids are necessary for pain relief or that it is their obligation to ensure adequate availability of opioid medicines. This was reported by three country teams. 
Other challenges to the availability and accessibility of opioids identified at the workshops

Other challenges identified during the workshops were difficulties in accessing opioids out-of-hours - particularly in rural areas because not all pharmacies stock opioids; an unequal geographical distribution of pain services due to financial reasons and a lack of trained specialists; or that patients not registered with a general practitioner or not admitted to hospital may not be able to get access to opioids.

National approaches to solution

To approach thedevelop national action plans the country teams completed so called strategic planning worksheets in group work (see-Table 2).

Table 2 Strategy planning worksheet - example education

\begin{tabular}{|c|c|c|}
\hline What? & A. State the problem & Education \\
\hline Why? & $\begin{array}{l}\text { B. State the underlying } \\
\text { reason(s) for the problem }\end{array}$ & $\begin{array}{l}\text { No standard training in opioid } \\
\text { analgesia in the basic } \\
\text { curriculum in physicians and } \\
\text { other health care professionals } \\
\text { No comprehensive continuing } \\
\text { education and training of } \\
\text { executives involved with the } \\
\text { subject }\end{array}$ \\
\hline What? & $\begin{array}{l}\text { C. State the objective }(\mathrm{s}) \text { that } \\
\text { would address the problem. } \\
\text { Which objectives are top } \\
\text { priorities }\end{array}$ & $\begin{array}{l}\text { Inclusion of } P C \text { and opioid } \\
\text { management in the basic } \\
\text { training of physicians and } \\
\text { paramedics } \\
\text { To overcome opiophobia }\end{array}$ \\
\hline How? & $\begin{array}{l}\text { D. What action steps are } \\
\text { needed to achieve the } \\
\text { objective? }\end{array}$ & $\begin{array}{l}\text { Target population of education: } \\
\text { Physicians, Nurses, Social } \\
\text { workers, Pharmacists, Patients } \\
\text { and Families, Public }\end{array}$ \\
\hline Who? & $\begin{array}{l}\text { E. List those who have the } \\
\text { authority and/or responsibility to } \\
\text { take the necessary action. }\end{array}$ & $\begin{array}{l}\text { Ministry of Education } \\
\text { Ministry of Health } \\
\text { Ministry of Justice }\end{array}$ \\
\hline When? & $\begin{array}{l}\text { F. Timeline for completion of } \\
\text { action steps }\end{array}$ & September 2011-October 2012 \\
\hline How Much? & $\begin{array}{l}\text { G. What technical and financial } \\
\text { assistance will be needed to } \\
\text { achieve each objective }\end{array}$ & $\begin{array}{l}\text { 1. Ministry of Health } \\
\text { 2.Ministry of Education } \\
\text { 3.Pharmaceutical Companies }\end{array}$ \\
\hline
\end{tabular}




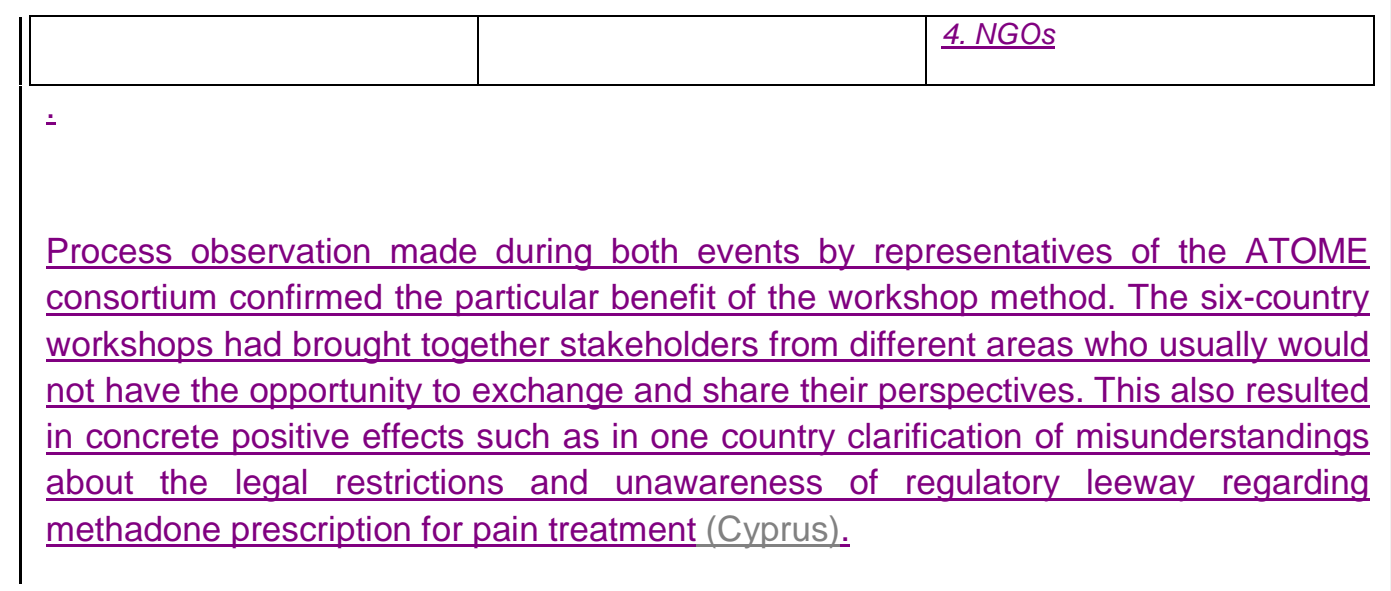

\section{Workshop evaluation}

$44 \%$ FourtyfourForty-four percent $(n=37)$ of the $84 \mathrm{~A}$ total of 37 participants completed both pre- and post-workshop questionnairesparticipants completed both pre- and post-workshop questionnaires, see Table 32. $\div 35$ ThintyfiveThirty-five of the 37 respondents (95\%) reported that their knowledge about accessibility of controlled medicines 'had been enhanced'- by attending the workshop $\overline{\bar{i}}_{1}$ and 21 (57\%) reported that their attitudes in relation to the accessibility of controlled medicines shad been changed' by attending the workshop.

Respondents made suggestions itn the questionnaire, suggestions were made to improve the situation; countries mentioned here can be seen as exemplary; the suggestions are likely to relate to other countries as well. Raising public awareness about the beneficial effects of opioids to reduce the fear of prescribing opioids medicines was suggested by several teams. Concrete measures were proposed, such as the initiation of social campaigns counteractionto counteract myths and stereotypes about opioids (-Poland, Serbia, Slovakia and Turkey), or raising pressure from professional organisations, trade unions, patient organisations and professional bodies to influence political will and ensure adequate reimbursement of opioids (Hungary).

The acknowledgement of chronic pain as a clinical problem was deemed of paramount importance (highlighted by a delegate from Bulgaria), and the development of policy guidelines in pain management in collaboration with the Ministry of Health to overcome barriers relatingrelated to excessive regulations was proposed by a representative from Cyprus.

In the questionnaire, suggestions were made to improve the situation. Raising public awareness about the beneficial effects of opioids to In the questionnaire section for possible improvements several recommendations have been made by the country teams. In relation to reduce the fear of prescribing opioids was suggested by the Estonian team, Estonian team members, recommended that public awareness about the beneficial effects of opioids should be raised on a regular basis in order to 
change attitudes. Poland, Serbia, Slovakia and Turkey suggested the initiation of that social campaigns counteracting myths and stereotypes about opioids should be initiated. Participants from Hungary recommended raising pressure from professional organisations, trade unions, patient organisations and professional bodies to influence political will and ensure adequate reimbursement of opioids.

To address the challenges associated with the lack of reimbursement for opioids, participants from Hungary recommended that the only way that opioids can be adequately reimbursed is through pressure from professional organisations, trade unions, patient organisations and professional bodies in order to influence political will. Bulgaria highlighted the need to acknowledge chronic pain as a clinical problem. Participants from Cyprus suggested the development of policy quidelines in pain management in collaboration with the Ministry of Health to overcome barriers relating te

To ease the challenges from excessive regulations.- related to storage and dispensing of opioids, Cyprus suggested that challenges to a lack of opioid legislation or inappropriate legislation could be overcome by developing policy guidelines in pain management in collaboration with the Ministry of Health.

\section{Discussion}

The results of the workshops demonstrate-underline that lack of access to opioids is a_multifactorial fieldin nature. Barriers exist on numerous levels which are interlocked and partially reinforced by each other. A strength of these workshops was therefore thatFor this reason, stakeholders representing as many relevant fields as possible in relation to access to opioids were addressed by this workshop.

Common challenges identified during the ATOME workshops were a number of educational, regulatory, legislational and training barriers that limit the ability of both physicians and nurses to prescribe the necessary doses of opioids to patients. A number of publications have been produced by the European Association for Palliative Care (EAPC) $[9,10]$ to overcome these challenges.- These findings are in line with the main barriers to opioid accessibility reported in previous publications by leading researchers in the field $[-11,12,13,14]$.

Other fFrequently reported challenges were related to short validity of prescriptions and excessive bureaucratic practices when prescribing. Similar results have been identified in the legislation analysis by Utrecht University during the ATOME project as well as in the individual country reports. The issue of overregulation of opioids was also reviewed by Cherny, et al., $[15,16,17]$ who reported on some elements of the legal and regulatory barriers to opioid availability and accessibility throughout Europe and the world. Unduly restrictive legislation that limits the distribution, prescription, dispensation, and use of opioids has been described by Joranson and Ryan [18] and Human Rights Watch [19]. These authors agree that in most cases the problem is it is not the lack of availability of opioids in the country, but rather the combination of many bureaucratic and legislative regulations that impede opioid prescription and 
dispensing. Many medical professionals, especially particularly family doctors, appear to be afraid of prescribing opioid medications, often related to these regulatory barriers [20]. Lynch, et al., [21] reported complicated procedures relating to the prescription of opioids in the countries of Central and Eastern Europe and Commonwealth of Independent States, where it was very difficult to obtain a license to prescribe opioids.

Limited knowledge about opioid analgesics was reported in a number of countries in Western Europe [22], where lack of professional knowledge about the prescription of strong opioids may result in reluctance on the part of physicians to prescribe them. The relevance of such challenges to a plethora of diverse socio-cultural, economic, educational and health policy settings should be fully and adequately considered.

Next to establishing national, regional, or local under- and postgraduate education opportunities for healthcare professionals, the availability of guidance papersquidelines or other quidance can be a possiblefeasible way to address unawareness and misinformation, such as the evidence-based quidelines by the European Association for Palliative Care (EAPC) on the use of opioid analgesics for the treatment of cancer pain [(23ref:]].

In relation to opioid agonist therapy, stigmatization and criminalization of people who use drugs remain the major impediment to increasing programme coverage, particularly in prison settings. This manifests a lack of interest among policy makers to invest in evidence-based harm reduction approaches, despite the proven effectiveness of these programmes in preventing HIV transmission. Fear of arrest and police harassment among drug users may deter many from accessing these services [5].

The aims of the workshops to assist the country teams to analyse their national situational, disseminate country-specific national action plans and raise the awareness about tools and resources have been realized. The challenges reported in the workshops have been analyzed and have been considered in subsequent steps of the programme such as the national follow-up conferences. Participants' feedback included some criticism on the schedule (too full); or that a longer meeting time of repeated events over a period of time might have provided better outcomes. However, nearly all participants reported that their expectations for the workshop had been met.

\section{Limitations}

There are a number of limitations associated with this paper. First of all, Tthe selection of experts and participants attending the workshops was a potential source of bias as. As-their views may not represent the situation in were subjective and isolated, they cannot be presumed to be completely representative of the countries concerned. However, the participants (ATOME country team members) were carefully selected to ensure that as many relevant fields as possible in relation to access to opioids were represented. This is crucial as limproving access to opioids requires a multilevel approach since it is the outcome of a complex interaction of 
national legislation, policies and regulations, education, economy/finance, healthcare practice, attitudes, and social norms. In addition, close collaboration with the country teams during all phases of the ATOME project, including thisthe workshops, ensured ownership of the proposed strategies which is an important prerequisite for successful implementation. Therefore, stakeholders representing as many relevant fields as possible in relation to access to opioids were invited to these workshops. The setting was prepared to ensure that the situational analysis, the identification of problems, and proposal of solutions were developed by the national stakeholders themselves.

In aAddition, there may also haveThere may have been some unintended negative effects during the workshops - for example the fact that data-challenges provided reported by participants or country teams could potentially have been inflated suppressed by competitive tendencies between neighbouring countries. However, the invitation of six different countries to each workshop was also believed to facilitate exchange, reduce stigma, and enhance the creative development of solutions by learning from models in other countries, since many countries do encounter similar problems.

Importantly, the challenges identified during each workshop only reflect what was explicitly discussed; this does not necessarily mean that the respective issues do not also apply to other countries- the barriers identified are not exclusive to the countries that reported them.

Similar wWorkshops with similar setup have been used to compare the development of health care policy across both countries and regions and have come to similar results; most notably, those undertaken by the Open Society Foundations International Palliative Care Initiative and regional or national palliative care associations such as the African Palliative Care Association (APCA) $[24,25,26]$ and the International Association for Hospice \& Palliative Care (IAHPC) [27]. The international comparison of barriers as well as the possibility of establishing new contacts in a similar field of expertise seems to be a fruitful way of resolving widespread difficulties.

Importantly, the challenges identified during each workshop only reflect what was explicitly discussed; this does not necessarily mean that the respective issues do not also apply to other countries the barriers identified are not exclusive to the countries that reported them.

\section{Conclusion}

The participants of the country teams made use of the two six-country workshops to identify key challenges to access to opioids in their country and to elaborate tailormade strategic action plans for improvement. Findings from the country workshops reported here were triangulated with outcomes from related activities in the ATOME project, most importantly the recommendations resulting from the in-depth analysis of 
legislation [30]. The results of these workshops therefore delivered an important contribution to a comprehensive analysis and informed the subsequent work of the country teams during a series of national follow-up conferences, as well as the development of tailor-made recommendations and solutions for each of the twelve participating countries [29]. These recommendations could serve as quidance for other countries in the world as well.

The WHO resolution on strengthening Palliative care, which has been adopted at the World Health Assembly in May 2014 in Geneva [28] gives hope that a global improvement of pain treatment gets to the focus of politicians and health care decision makers. As to the furtherThe action steps resulting from the identified challenges the ATOME programme developedwith tailor-made solutions for each of the twelve particitpatingparticipating countries that could accountcould set an example for other countries in the world as well that want to improve access to controlled medicines following the WHO resolution[29].

Many The challenges to access to opioids were identified during the workshops These challenges, as well as key topics from the national action plans developed in the workshops were used to inform the work of the country teams during a series of national follow-up conferences. Importantly, legislation and regulations concerning the use of controlled medicines have been analysed in depth by Utrecht University as part of the ATOME project [30]. Findings from the country workshops reported here, the results of the legislation review and the results of the national follow-up conferences have been used for triangulation. Finally, a report on the findings in each participating country has been compiled and will be presented to the national health ministries.

The WHO resolution on strengthening Palliative care, which has been adopted at the World Health Assembly in May 2014 in Geneva [31] gives hope that a globat improvement of pain treatment gets to the focus of politicians and health care decision makers. As to the further steps resulting from the identified challenges the ATOME programme developed tailor made solutions for each of the twelve particitpating countries that could account for other countries in the world as well [32].

Word Count: 2604

Date: 12th Mayi 2015

\section{Acknowledgements}


The research leading to these results has received funding from the European Community's Seventh Framework Programme [FP7/2007-2013] under grant agreement $n^{\circ} 222994$. This paper was prepared on behalf of the ATOME consortium which wais composed of ten partners from the fields of palliative care (Department of Palliative Medicine, University of Bonn, Bonn, Germany; Hospice Casa Sperantei, Brasov, Romania; Help the Hospices, London, UK; International Observatory on End of Life Care, Lancaster University, Lancaster, UK; European Association for Palliative Care, Milan, Italy); law/health policy ( $\div$ Utrecht University, Utrecht, The Netherlands); harm reduction (Eurasian Harm reduction Network, Vilnius, Lithuania; Harm Reduction International, London, UK) and governance (World Health Organization, Geneva, Switzerland; National Anti-Drug Agency, Bucharest, Romania). Together, this group consistsed of national, European-wide and international organisations with long-standing experience in opioid medicine issues; the ten ATOME partners worked with the country teams, including government officials and public-health and medicines experts, to carry out legislative and policy reviews, leading to recommendations that will facilitate access for all patients requiring treatment with | medicines controlled under international drug conventions. (www.atome-project.eu).

\section{References}

1 Pain \& Policy Studies Group, University of Wisconsin-Madison. International Narcotics Control Board; United Nations population data: Opioid Consumption Maps - Morphine Equivalence, mg/capita, 2012. Copyright @ 2009-2015 The Board of Regents of the University of Wisconsin System. https://ppsg.medicine.wisc.edu/ (accessed12th January 2015).

2 Paudel BD, Ryan KM, Brown MS, et al. Krakauer EL, Rajagopal MR, Maurer MA, Gleary JF.Opioid Availability and Palliative Care in Nepal: Influence of an International Pain Policy Fellowship. J Pain Symptom Manage 2015 Jan;_49(1):1106. Epub 2014 Apr 21.

\section{Seya MJ, Gelders SFAM, Achara UA, Milani B, Scholten WK. A First Comparison} between the Consumption of and the Need for Opioid Analgesics at Country, Regional and Global Level. J Pain and Palliative Care Pharmacotherapy; 2011; 25: $\underline{6-18 .}$

4 B-Duthey B and W-Scholten W. Adequacy of opioid analgesic consumption at country, global and regional level in 2010, its relation to development level and changes compared to 2006. J of Pain and Symptom Management 2014; 47(2): 28397 .

5 Global State of Harm Reduction: Towards an integrated response. Stoicescu C (ed.). Harm Reduction International, London, 2012. 
6 Lynch $_{\bar{i}} \mathrm{~T}_{-}$, Payne, $\mathrm{S}_{\bar{i}}$, Scholten $\mathrm{W}_{\bar{i}}$, Jüunger $\mathrm{S}_{\bar{i}}$, and-Radbruch, L. 2011. ATOME training of lawyers and national counterparts workshop: a report. European Journal of Palliative Care, vol. 18(6): 293-297.

7 World Health Organizantion, 2011. Ensuring Balance in National Policies on Controlled Substances, Guidance for Availability and Accessibility of Controlled Medicines. Geneva: WHO.

9-Caraceni A, Cherny N, Fainsinger R, Kaasa S, Poulain P, Radbruch L, De Conno $\mathrm{F}$ : Steering Committee of the EAPC Research Network. Pain Measurement Tools and Methods. Recommendations of an Expert Working Group of the EAPC. J Pain and Symptom Manage 2002; 23(3): 239-255.

10 King S, Forbes K, Hanks GW, Ferro CJ, Chambers EJ.: A systematic review of the use of opioid medication for those with moderate to severe cancer pain and renal impairment: A European Palliative Care Research Collaborative opioid guidelines project. Palliat Medicine. 2011; 25(5):525-52.

11 Cleary JF, Hutson P, Joranson D. :-Access to therapeutic opioid medications in Europe by 2011? Fifty years on from the single convention on narcotic drugs. Palliat Med 2010; 24:109-110.

12 Gilson AM, Maurer MA, Lebaron VT, et al.Ryan KM, Cleary JF: Multivariate analysis of countries' government and health-care system influences on opioid availability for cancer pain relief and palliative care: more than a function of human development. Palliat Med. 2013; 27(2):105-14. doi: 10.1177/0269216312461973. Epub 20120ct 26.

13 Joranson DE, Ryan KM. Ensuring opioid availability: Methods and resources. J Pain Symptom Manage 2007; 33:527-532.

14 Joranson DE, Ryan KM, Maurer MA. Opioid policy, availability and access in developing and nonindustrialized countries. In: Fishman SM, Ballantyne JC, Rathmell JP, eds. Bonica's Management of Pain. 4th ed. Baltimore, MD: Lippincott Williams \& Wilkins; 2010;194-208.

15 Cherny $\mathrm{NI}$, Catane R, Kosmidis PA.-Problems of opioid availability and accessibility across Europe: ESMO tackles the regulatory causes of intolerable and needless suffering. Ann Oncol 2006; 17(6): 885-887.

16 Cherny NI, Baselga J, de Conno F,-et alRadbruch L._-Formulary availability and regulatory barriers to accessibility of opioids for cancer pain in Europe: a report from the ESMO/EAPC Opioid Policy Initiative. Ann Oncol 2010; 21(3): 615-26.

17 Cherny NI, Cleary J, Scholten W, et al. The Global Opioid Policy Initiative (GOPI) project to evaluate the availability and accessibility of opioids for the management of 
cancer pain in Africa, Asia, Latin America and the Caribbean, and the Middle East: introduction and methodology. Ann Oncol 2013; 24(11): xi7-xi13.

18 Joranson $\mathrm{DE}$, Ryan $\mathrm{KM}_{-}:$Ensuring opioid availability Methods and resources. $J$ Pain Symptom Manage 2007; 33: 527-532.

19 Human Rights Watch: "Please, do not make us suffer any more." Access to Pain Treatment as a Human Right. New York: Human Rights Watch, 2009. https://www.hrw.org/report/2009/03/03/please-do-not-make-us-suffer-anymore/access-pain-treatment-human-right (accessed_10ㅈth July May_2013므).

20 Krakauer EL, Wenk R, Buitrago R, -et al:-. Opioid inaccessibility and its human consequences: reports from the field. J Pain Palliat Care Pharmacother 2010; 24(3):239-43.

21 Lynch T, Clark D, Centeno C, -et al.Rocafort J, Flores LA, Greenwood A, Praill D, Brasch S, Giordano G, De Lima L, Wright W: Barriers to the Development of Palliative Care in the Countries of Central and Eastern Europe and the Commonwealth of Independent States. J of Pain and Symptom Manage 2009; 37(3): 305-315.

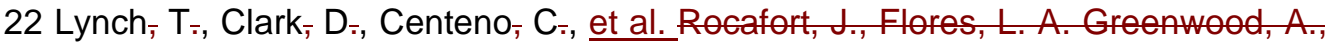
Praill, D., Brasch, S., Giordano, A., De Lima, L., Wright, M:-Barriers to the development of palliative care in Western Europe. Palliative Medicine 2010; 24(8): 812-819.

23 Caraceni A, Hanks G, Kaasa S, et al.:- Use of opioid analgesics in the treatment of cancer pain: evidence-based recommendations from the EAPC. Lancet Oncol 2012; 13(2):p58-68. doi: 10.1016/S1470-2045(12)70040-2.

24 Assuring Availability and Accessibility of Opioid Medicines in the Eastern Mediterranean Region: Marrakech, Morocco December 6th to 8th, 2010 Workshop report. Ddungu H. African Palliative Care Association, Kampala, 2011.

25 Advocacy Workshop for Palliative Care in Africa: A Focus on Essential Pain Medication Accessibility: Entebbe, Uganda 27th - 29th June 2006, Workshop report. African Palliative Care Association, Kampala, 2011.

26 Advocacy Workshop for Palliative Care in Africa: A focus on essential pain medication accessibility in Southern Africa: Windhoek, Namibia 27th - 29th February 2008, Workshop report. African Palliative Care Association, Kampala, 2011.

27 International Association for Hospice \& Palliative Care (IAHPC): Message from the Chair and Executive Director, Opioid Availability Workshops. IAHPC newsletter, 
2011; Volume 12, No 04, April. http://www.hospicecare.com/news/11/04/chair.html (accessed 30th March 2015).

28 World Health Organization, 2014. Strengthening of palliative care as a component of integrated treatment within the continuum of care. Geneva: WHO. Accessible at: http://apps.who.int/gb/ebwha/pdf_files/EB134/B134_R7-en.pdf.

29 Access to Opioid Medication in Europe (ATOME): Final Report and Recommendations to the Ministries of Health (English Edition). Radbruch L, Juenger S, Payne S and Scholten W (eds). Pallia Med Verlag Bonn 2014. ISBN 9783-933154-60-6.

30 Vranken MJ, Mantel-Teeuwisse AK, Junger S, Radbruch L, Lisman J, Scholten W, et al. Legal Barriers in Accessing Opioid Medicines: Results of the ATOME Quick Scan of National Legislation of Eastern European Countries. J Pain Symptom Manage 2014;48(6):1135-44.

31 World Health Organization, 2014. Strengthening of palliative care as a component of integrated treatment within the continuum of care. Geneva: WHO. Accessible at: http://apps.who.int/gb/ebwha/pdf_files/EB134/B134_R7-en.pdf.

32 Access to Opioid Medication in Europe (ATOME): Final Report and Recommendations to the Ministries of Health (English Edition).

L, Radbruch, S, Payne S and Scholten W (eds). Pallia Med Verlag Bonn 2014. ISBN 978-3-933154-60-6

Table 1: challenges concerning access to opioids identified by the country teams

\begin{tabular}{|c|c|c|}
\hline Identified challenge & $\begin{array}{l}\frac{\text { No. of }}{\text { country }} \\
\text { teams }\end{array}$ & $\frac{\text { Recommendations elaborated among the }}{\text { country teams }}$ \\
\hline $\begin{array}{l}\text { ILack of education: } \\
\frac{\text { Inandequate training of physicians in }}{\text { pain management. Many general }} \\
\text { practitioners therefore refer the } \\
\text { prescription of opioids to oncologists } \\
\text { resulting in underprescription. }\end{array}$ & $\underline{9}$ & $\begin{array}{l}\text { Implement opioid prescribing examination, } \\
\text { improve education in the field of pain } \\
\text { management, educate regulatory authorities } \\
\frac{\text { to underline that access to pain relief is a }}{\text { human right, and develop a network to }} \\
\frac{\text { educate multidisciplinary teams in }}{\text { prescribing. }}\end{array}$ \\
\hline
\end{tabular}

Field Code Changed

Field Code Changed

Field Code Changed
Field Code Changed

Field Code Changed

Formatted: English (U.S.) 


\begin{tabular}{|c|c|c|}
\hline $\begin{array}{l}\text { ILack of knowledge about opioids } \\
\text { amongst patients, their family and } \\
\text { society: } \\
\frac{\text { Fears and beliefs as well as mis- }}{\text { information and misunderstanding. }} \\
\frac{\text { Perception that suffering is normal, }}{\text { necessary or heroic. Negative }} \\
\frac{\text { stereotypes about opioids ("drugs") }}{\text { reinforce the fear of patients and }} \\
\text { physicians. }\end{array}$ & $\underline{7}$ & $\frac{\text { raise public awareness about the beneficial }}{\text { effects of opioids }}$ \\
\hline $\begin{array}{l}\frac{\text { LLack of recognition of pain }}{\text { management: }} \\
\frac{\text { Chronic pain and other non- }}{\text { oncological diagnoses are often not }} \\
\frac{\text { being recognised by healthcare }}{\text { professionals. }}\end{array}$ & $\underline{5}$ & $\begin{array}{c}\text { develop policy guidelines in pain } \\
\text { management in collaboration with the } \\
\frac{\text { respective ministry, recognise/acknowledge }}{\text { chronic pain and pain of non-cancer as a }} \\
\text { clinical problem (with an ICD code if possible) }\end{array}$ \\
\hline $\begin{array}{l}\text { Lack of reimbursement: } \\
\text { Due to high costs opioids are not } \\
\frac{\text { being reimbursed for acute or }}{\text { chronic conditions. The lack of }} \\
\frac{\text { recoginition of chronic non-cancer }}{\text { pain as a medical condition makes }} \\
\underline{\text { reimbursement impossible. }}\end{array}$ & $\underline{6}$ & $\begin{array}{l}\frac{\text { achieve adequat reimbursed through }}{\text { pressure from professional organisations, }} \\
\frac{\text { trade unions, patient organisations and }}{\text { professional bodies in order to influence }} \\
\text { political will }\end{array}$ \\
\hline $\begin{array}{l}\frac{\text { Limitations to the avialable range }}{\text { of opioids: }} \\
\text { Lack of choice of opioids such as } \\
\frac{\text { injectable morphine, slow-release }}{\text { oral morphine, buprenorphine and }} \\
\text { methadone. }\end{array}$ & $\underline{5}$ & $\frac{\begin{array}{l}\text { bring the revised WHO list of essential } \\
\text { medicines to the adherence of government }\end{array}}{\frac{\text { representatives and the pharmaceutical }}{\text { industry }}}$ \\
\hline $\begin{array}{l}\frac{\begin{array}{l}\text { Pharmaceutical company } \\
\text { reluctance to manufacture } \\
\text { opioids: }\end{array}}{\frac{\text { Some pharmaceutical companies }}{\text { have little interest in procuring }}} \\
\frac{\text { opioids as there is only a small }}{\text { market where cost of procurement }} \\
\frac{\text { and projected incomes are }}{\text { disproportional. }}\end{array}$ & $\underline{3}$ & $\begin{array}{l}\text { establish a reliable supply of slow-release } \\
\text { oral morphine (if needed via import) and } \\
\text { improve access to immediate-release opioids }\end{array}$ \\
\hline
\end{tabular}




\begin{tabular}{|c|c|c|}
\hline $\begin{array}{l}\text { Excessive regulations relating to } \\
\text { the prescribing of opioids: } \\
\text { Special prescription forms that need } \\
\text { to be stored with special security } \\
\frac{\text { measures, restrictions regarding the }}{\text { authorisation to prescribe, excessive }} \\
\frac{\text { reporting requirements of opioid }}{\text { prescriptions, complicated }} \\
\frac{\text { administrative requirements for filling }}{\text { out the prescriptions and limited }} \\
\text { prescription. }\end{array}$ & $\underline{8}$ & $\frac{\frac{\text { e-prescription forms should be introduced to }}{\text { enable every physician to prescribe opioids }}}{\frac{\text { without having to complete a special }}{\text { prescription form }}}$ \\
\hline $\begin{array}{l}\frac{\text { Excessive regulations relating to }}{\text { storage and dispensing of }} \\
\text { opioids: } \\
\frac{\text { Not all pharmacies are allowed to }}{\text { store opioids and special storage }} \\
\text { conditions are required. }\end{array}$ & $\underline{5}$ & $\begin{array}{l}\text { special licensing for dispensing opioids } \\
\text { should be abolished, and all pharmacies } \\
\text { should be leqally obliged to dispense them }\end{array}$ \\
\hline $\begin{array}{l}\frac{\text { Lack of opioid legislationl }}{\text { inappropriate legislation: }} \\
\text { Lack of legislation and outdated } \\
\text { terminology impede an adequate } \\
\text { supply. }\end{array}$ & $\underline{5}$ & $\begin{array}{l}\text { revise legislation with the aim of addressing } \\
\text { fears and myths relating to the use of opioids }\end{array}$ \\
\hline $\begin{array}{l}\frac{\text { Focus on suppression rather than }}{\text { availability of opioids: }} \\
\text { Government agencies tend to focus } \\
\frac{\text { more on prevention of diversion and }}{\text { misuse rather than medical }} \\
\frac{\text { availability of opioids and have little }}{\text { recognition that opioids are }} \\
\text { necessary for pain relief. }\end{array}$ & $\underline{3}$ & $\begin{array}{c}\begin{array}{c}\text { education/training sessions and opioid } \\
\text { workshops amongst regulatory authorities }\end{array} \\
\text { that stress access to pain relief as a 'human } \\
\underline{\text { right' }}\end{array}$ \\
\hline $\begin{array}{l}\text { Other challenges identified: } \\
\frac{\text { Difficulties in accessing opioids out- }}{\text { of-hours (rural areas) and a lack of }} \\
\underline{\text { trained specialists. }}\end{array}$ & $\underline{1}$ & $\frac{\text { all pharmacies should be permitted to stock }}{\text { opioids }}$ \\
\hline
\end{tabular}

Table 3: Extract of results from the post-workshop questionnaire

\begin{tabular}{||l|l||}
\hline \hline 1. & What was the most valuable aspect of the workshop? \\
\hline \hline & Opportunity to collaborate with the government on a project \\
\hline & Exchanging information with other countries \\
\hline & Meeting people working in the same field in other countries \\
\hline & Experience of other countries and recommendations \\
\hline & I was able to convince my country team and raise awareness especially in the Ministry of Health \\
\hline
\end{tabular}




\begin{tabular}{||l|l||}
\hline & Country action plans gave a good overview of the problematic situation \\
\hline \hline 2. & What was the least valuable aspect of the workshop? \\
\hline \hline & $\begin{array}{l}\text { Too hard working the whole day requiring full concentration } \\
\text { quality of work }\end{array}$ \\
\hline \hline & $\underline{\text { Too much time is spent on the action plan }}$ \\
\hline \hline & $\begin{array}{l}\text { Please write down any additional comments or sugqestions } \\
\text { financial problems }\end{array}$ \\
\hline & $\begin{array}{l}\text { Everything was well organized; maybe more teaching, films, case examples can be included in } \\
\text { the programme }\end{array}$ \\
\hline & \begin{tabular}{l} 
Good balance of theory and information and practical work \\
\hline
\end{tabular} \\
\hline
\end{tabular}

